\title{
Outcome of Preterm Admissions at the Neonatal Unit of a Tertiary Care Military Hospital of Bangladesh
}

\author{
BK RAHA $^{\mathrm{a}}$, MT UDDIN ${ }^{\mathrm{b}}$, MNURUNNABI $^{\mathrm{c}}$
}

\begin{abstract}
:
Introduction: Preterm deliveries contribute to major morbidity and mortality in developing countries. They are a leading cause of admission in neonatal care units. It is a major hindrance to the attainment of the Sustainable Development Goal (SDG)-3 targets given its high contribution to neonatal mortality. Early detection of its risk factors and advances in the management have ensured better survival of preterm births. This study was conducted to determine the prevalence, underlying causes, morbidity patterns and outcome of preterm admissions to a neonatal intensive care unit (NICU) of a tertiary care center in Combined Military Hospital (CMH) Sylhet.

Material and Methods: A descriptive study was conducted in CMH Sylhet from July 2018 to June 2020. All live preterm babies delivered at CMH Sylhet during the study period were included. Information obtained included gestational age at birth, gender, cause for preterm birth, problems during admission and outcome.

Results: During this period, a total of 662 neonates were admitted out of which 107 (16.2\%) were preterm with gestational ages ranging from 27 completed weeks to less than 37 completed weeks with a mean gestational age 33.2 weeks ( \pm 2.7 weeks) and birth weights from $800-2600 \mathrm{gm}$ with a mean of $2100 \mathrm{gm}( \pm 700 \mathrm{gm})$. There were 52 males and 55 females (M: F 0.95). One hundred and thirty three (20.1\%) were delivered by normal vaginal delivery while 529 (79.9\%) were delivered by Caesarean section. The
\end{abstract}

Introduction:

Gestational age (GA) is a key determinant of newborn survival. Preterm birth, defined as the birth of an infant

a. Lt Col (Dr.) Biplob Kumar Raha, Classified Specialist in Paediatrics Combined Military Hospital Sylhet Jalalabad Cantonment

b. Col (Dr.) Mohammad Taslim Uddin, Commandant, Combined Military Hospital, Sylhet, Jalalabad Cantonment.

c. Col (Dr.) MD. Nurunnabi, Haematologist, Combined Military Hospital Sylhet Jalalabad Cantonment.

Address of Correspondence: Dr. (Lt Col) Biplob Kumar Raha, FCPS (Paediatrics), Classified Specialist in Paediatrics, Combined Military Hospital Sylhet, Jalalabad Cantonment. Mobile no: 01716942580,E-mail: biplob101584@gmail.com,

Received: 03 February, 2021 Accepted: 26 October 2021 duration of hospital stay ranged from 1 - 45 days, with a mean duration of 15 days ( \pm 9.2 days). The commonest reason for prematurity was premature rupture of membrane (PROM) (39.3\%) followed by gestational diabetes mellitus (GDM) (35.5\%), hypertensive disorders in pregnancy (30.8\%), multiple pregnancy (29.9\%) and inadequate ante natal care (ANC) (20.6\%). The commonest morbidity in the patients in the present study was neonatal jaundice (90.7\%) followed by respiratory problems (78.5\%), sepsis (17.8\%) and congenital heart disease (CHD) (15.9\%). Case fatality rate for patients with respiratory distress syndrome (7.7\%) and sepsis (5.3\%) were common. Overall survival rate was $91.6 \%$ and was significantly $(p<0.001)$ higher in the moderate to late preterm category compared to the very preterm and extremely preterm births.

Conclusion: PROM, GDM, hypertensive disorders in pregnancy, multiple pregnancy and inadequate ante natal care were significantly associated with preterm birth. Neonatal jaundice, respiratory problems, sepsis and CHD were common morbidities observed. Case fatality rate was significant in neonates with respiratory distress syndrome and sepsis and overall survival rate was $91.6 \%$. So, at-risk mothers should receive intensified antenatal care to mitigate preterm birth.

Keywords: Preterm, Gestational age, Risk factors, Morbidity, Outcome.

(J Bangladesh Coll Phys Surg 2022; 40: 39-44) DOI: https://doi.org/10.3329/jbcps.v40i1.57056

before 37 completed weeks of gestation, is the leading cause of death in children before the age of 5 years globally and accounts for one-third of the neonatal deaths ${ }^{1}$. The worldwide average proportion of preterm births was estimated at $11 \%$ in 2014 , corresponding to 15 million children born too soon annually ${ }^{2}$. Over $80 \%$ of these preterm births occur in South Asia and subSaharan Africa. In a global comparison, Bangladesh has the highest proportion of preterm births with $19 \%$ of births occurring before gestational age week $37^{2}$. Eighty five percent preterm are born between 32-37 weeks of gestation ${ }^{3}$.

The WHO classification categorizes preterm births into extreme preterm ( $<28$ completed weeks), very preterm 
( 28 - $<32$ completed weeks), and moderate to late preterm (32 - $<37$ completed weeks) ${ }^{4}$.

Common risk factors of preterm birth include premauture rupture of membrane (PROM), multiple pregnancies, infections and chronic conditions such as diabetes and high blood pressure; however, often no cause is identified ${ }^{4}$. There could also be a genetic influence ${ }^{4}$. According to Pennell et al. approximately $45 \%$ to 50\% of preterm births are idiopathic, $30 \%$ are related to preterm rupture of membranes and another $15 \%$ to $20 \%$ result from medically indicated or elective preterm deliveries ${ }^{5}$.

Despite good neonatal care, premature deliveries have short term consequences like feeding difficulties, hypothermia, hypoglycemia, respiratory distress syndrome (RDS), apnoea of prematurity, jaundice, sepsis and necrotizing enterocolitis (NEC) while long term consequences include motor disability and cognitive problems ${ }^{6}$. Factors that influence the success in the management of prematurity include level of prenatal care, gestational age at birth, sex, availability of resources and adequate and well trained personnel ${ }^{7}$.

WHO developed new guidelines with recommendations for improving outcomes of preterm births. The guidelines include interventions provided to the mother - for example steroid injections before birth, antibiotics when her water breaks before the onset of labor, and magnesium sulfate to prevent future neurological impairment of the child - as well as interventions for the newborn baby - for example thermal care, feeding support, kangaroo mother care, safe oxygen use, and other treatments to help babies breathe more easily ${ }^{8}$. It is necessary to carry out neonatal audit regularly as disease patterns vary from place to place and even from time to time in the same place ${ }^{9}$.

The evolution of neonatal intensive care is one of the recent advances that ensures survival of the preterm neonate but this is not readily available in most developing countries ${ }^{10}$. Present study was conducted to determine the prevalence, morbidity patterns and outcome of preterm admissions and to identify the underlying causes for the same.

Material and Methods:

This descriptive study was carried out at NICU, CMH Sylhet during July 2018 to June 2020. All preterm babies admitted into the NICU of CMH Sylhet born at gestational ages of 27 completed weeks to less than 37 completed weeks of gestation were included into the study while those born at or after 37 completed weeks were excluded. The ethical approval of the study was obtained from ethical review committee of the area headquarter, Sylhet cantonment, Sylhet. Inform consent was taken from parents before enrollment. Data were collected by checkup sheet and appropriate questionnaire who were admitted in NICU.

After the initial assessment and cardio respiratory management, a history was obtained. Maternal and obstetrical histories were taken which provided invaluable information. Intra-partum details with special reference to the fetal well-being, maternal age, level of education, occupation, smoking and alcohol use during pregnancy, date of last normal menstrual period, antenatal care visits, duration of rupture of membranes, gestational diabetes mellitus (GDM), history of previous preterm birth, hypertensive disorders in pregnancy, multiple pregnancy, antepartum hemorrhage (APH), twin pregnancy, teenage mother and history of burning sensation during pregnancy or treatment for urinary tract infection (UTI) were recorded. Mode of delivery, onset of labor. APGAR score, resuscitation details, sex, and gestational age was assessed by modified Ballard score and clinical examination, and birth weight were also noted.

Data regarding the duration of hospital stay, problems during the period of admission and outcome of preterm admission were also recorded. They were classified into three 3 main categories according to gestational age at birth with those born between 32 to less than 37 completed weeks classified as moderate to late preterm and 28 to less than 32 completed weeks very preterm and less than 28 completed weeks as extremely preterm for birth. Statistical analysis was performed using the commercial statistical software Epi info version 3.5. P value less than 0.05 was considered statistically significant.

\section{Results:}

During the study period, a total of 662 neonates were admitted, out of which 107 (16.2\%) preterm with gestational ages were ranging from 27 completed weeks to less than 37 completed weeks and birth weights from $800 \mathrm{gm}$ to $2600 \mathrm{gm}$. The mean gestational age was 33.2 weeks ( \pm 2.7 weeks) with a mean birth weight of $2100 \mathrm{gm}$ 
$( \pm 700 \mathrm{gm})$. There were 52 males and 55 females $(\mathrm{M}: \mathrm{F}$ 0.95). One hundred thirty three (20.1\%) were delivered by spontaneous vaginal delivery while $529(79.9 \%)$ were delivered by Caesarean section. The duration of hospital stay ranged from 1 - 45 days, with a mean duration of 15 days ( \pm 9.2 days).

Mean gestational age of $33.2 \pm 2.7$ weeks. Most patients $(94,87.8 \%)$ were born between gestational ages of 32 and less than 37 completed weeks (Table I).

Table-I

\begin{tabular}{|c|c|c|}
\hline \multicolumn{3}{|c|}{$\begin{array}{c}\text { Distribution of Neonates by Their Gestational } \\
\text { Ages }(N=107)\end{array}$} \\
\hline Gestational age & Frequency & Percentage \\
\hline Extremely preterm & \multirow[t]{2}{*}{2} & \multirow[t]{2}{*}{1.9} \\
\hline$<28$ completed weeks & & \\
\hline Very preterm & \multirow[t]{2}{*}{11} & \multirow{2}{*}{10.3} \\
\hline 28 to $<32$ completed weeks & & \\
\hline Moderate to late preterm & \multirow[t]{2}{*}{94} & \multirow[t]{2}{*}{87.8} \\
\hline 32 to $<37$ completed weeks & & \\
\hline Total & 107 & 100 \\
\hline
\end{tabular}

The commonest cause for preterm birth was PROM in 42 (39.3\%) of the patients followed by GDM in 38 (35.5\%). Others are shown in Table II.
Table-II

Maternal Risk Factors for Preterm Births $(N=107)$

Maternal Risk Factors $\quad$ Frequency $\quad$ Percentage

\begin{tabular}{lll}
\hline PROM & 42 & 39.3
\end{tabular}

GDM

$38 \quad 35.5$

Hypertensive disorders $\quad 33 \quad 30.8$

in Pregnancy

Multiple Pregnancy $\quad 32 \quad 29.9$

$\begin{array}{lll}\text { Inadequate ANC } & 22 & 20.6\end{array}$

Previous preterm delivery $\quad 21 \quad 19.6$

$\begin{array}{lll}\text { UTI } & 17 & 15.9\end{array}$

$\begin{array}{lll}\text { Teenage mother } & 13 & 12.1\end{array}$

APH $\quad 11 \quad 10.3$

\begin{tabular}{lll} 
Twin pregnancy & 7 & 6.5 \\
\hline
\end{tabular}

Neonatal jaundice was present in $90.7 \%$ followed by TTN in $38.3 \%$, RDS in $24.3 \%$, and sepsis in $17.8 \%$ and CHD in $15.9 \%$ cases. Case fatality rate was $7.7 \%$ in RDS and $5.3 \%$ in sepsis (Table III).

The overall survival rate was $91.6 \%$. The survival rate was significantly higher in the moderate to late preterm category compared to the very preterm and extremely preterm for birth categories. This difference was statistically significant $(p<0.001)$ (Table IV).

Table-III

\begin{tabular}{lcccc}
\multicolumn{5}{c}{ Morbidity and Mortality Patterns in } \\
Morbidity & Frequency & Percentage & Mortality & Case Fatality Rate \\
\hline Jaundice & 97 & 90.7 & 0 & 0.00 \\
Respiratory problems & 84 & 78.5 & 2 & 2.38 \\
a. Transient tachypnea of newborn (TTN) & 41 & 38.3 & 0 & 0.00 \\
b. Respiratory distress syndrome (RDS) & 26 & 24.3 & 2 & 7.69 \\
c. Perinatal asphyxia & 5 & 4.7 & 0 & 0.00 \\
d. Apnea & 12 & 11.2 & 0 & 0.00 \\
Sepsis & 19 & 17.8 & 1 & 5.26 \\
Congenital heart disease (CHD) & 17 & 15.9 & 0 & 0.00 \\
Hypocalcaemia & 9 & 8.4 & 0 & 0.00 \\
Seizures & 7 & 6.5 & 0 & 0.00 \\
Birth defects & 5 & 4.7 & 0 & 0.00 \\
\hline
\end{tabular}


Table-IV

Association between Category of Prematurity and Clinical Outcome (N=107)

\begin{tabular}{lccc} 
Prematurity category & \multicolumn{2}{c}{ Outcome } & $\begin{array}{c}\mathrm{p} \text { value } \\
<0.001\end{array}$ \\
\cline { 2 - 4 } & Death & Discharged & $\begin{array}{c}\text { Transferred } \\
\text { to CMH Dhaka }\end{array}$ \\
\hline Extremely preterm $<28$ completed weeks & 1 & 1 & 0 \\
Very preterm 28 to $<32$ completed weeks & 2 & 5 & 4 \\
Moderate to late preterm32 to $<37$ completed weeks & 0 & 92 & 2 \\
\hline Total $(\%)$ & $3(2.8 \%)$ & $98(91.6 \%)$ & $6(5.6 \%)$ \\
\hline
\end{tabular}

\section{Discussion:}

Neonatal mortality attributable to preterm birth and complications remains a huge challenge globally. Most developing countries lack data on the prevalence of preterm birth ${ }^{4,11}$. In present study preterm admissions constituted $16.2 \%$ of all admissions at NICU of CMH Sylhet. Results from the present study are comparable with results from developed and developing countries with reported prevalence rates of $12 \%$ in North Central Nigeria $^{12}, 18.3 \%$ in Nairobi, Kenya ${ }^{13}, 20 \%$ in Matlab, Bangladesh $^{14}, 16.48 \%$ in western Nepal ${ }^{15}$ and $14 \%$ in South India ${ }^{16}$.

There were more preterm females than males in the present study similar to the study by Gupta A et al. ${ }^{16}$, McGil Ugwu et al. ${ }^{17}$ and Zeleke et al. ${ }^{18}$ Eleven (10.3\%) of the patients were born at 28 to less than 32 completed weeks gestation followed by $2(1.9 \%)$ born at less than 28 weeks gestation. Most of the patients $(87.8 \%)$ were born between gestational ages of 32 and less than 37 completed weeks.

The commonest reason for prematurity was PROM followed by multiple pregnancy and inadequate ANC. This was similar to findings by Kunle-Olowu et al. ${ }^{19}$ Kuppusamy et al. ${ }^{20}$ and Uma et al. ${ }^{21}$ from India reported PROM as a major risk factor for prematurity. Shrestha et al. ${ }^{22}$ reported lack of antenatal care as the commonest risk factor for preterm deliveries which is similar to the study by Kunle-Olowu et al. ${ }^{19}$ Other studies in Nigeria 23,24 have reported multiple pregnancy as a risk factor for preterm delivery. Multiple pregnancy has been shown to contribute to the high percentage of preterm deliveries ${ }^{25}$ with an average gestational age of twin births at 35 weeks. ${ }^{26}$

Medical conditions such as hypertension are documented cause for preterm delivery and this was established in the present study. This is similar to reports from other authors in Nepal ${ }^{22}$, Nigeria ${ }^{23}$ and Thailand 27 . A study was carried out on neonatal morbidity pattern in infants born to mothers with hypertensive disorders in pregnancy in Benin City, Nigeria ${ }^{28}$ were the rate of preterm delivery was significantly higher in the hypertensive mothers compared to their normotensive counterparts. About nineteen percent patients in the present study had history of preterm delivery in the previous pregnancies. Pandey et al. ${ }^{29}$ also concluded that prior preterm birth is a risk factor for preterm labor and it was identified in $14.4 \%$ subjects in their study group. UTI in pregnancy was associated with premature birth. This was similar to findings by Muglia et al. ${ }^{30}$

The commonest morbidity in the babies in present study was neonatal jaundice followed by respiratory problems and sepsis. This is similar to reports by Shrestha et al. ${ }^{22}$ and Khan et al. ${ }^{31}$ in Karachi, Pakistan who reported jaundice and sepsis as the commonest morbidity in their preterms. Onwuanaku et al. ${ }^{32}$ in Jos, Nigeria, reported sepsis as the commonest morbidity followed by jaundice. Onalo and Olateju ${ }^{33}$ in Abuja, Nigeria also reported jaundice as the commonest morbidity in their preterm patients. Infection control is very crucial in the management of preterm babies who are a high-risk group as a result of their immature immune system ${ }^{34}$. The case fatality rate was $7.7 \%$ in preterms with RDS followed by sepsis. Shrestha et al. ${ }^{22}$ also reported respiratory problems as the commonest cause of death in their preterm infants.

The overall survival rate was $91.6 \%$ which increased with increasing gestational age in present study and only one of the two babies born before 28 weeks survived. The survival rate was significantly higher in 
the moderate to late preterm category compared to the very preterm and extremely preterm for birth categories and this difference was statistically significant. Survival rate was $95 \%$ in a study by Ankur Gupta et al. ${ }^{16}$ and $65.9 \%$ in a study by Kunle-Olowu et al. ${ }^{19}$ with survival of only one (11.1\%) of the nine babies born at less than 28 weeks. The mortality was low in present study, this is at same to reports from Netherlands 2007 reports and Qatif Central Hospital, Saudi Arabia were the mortality was low. This further buttresses the importance of establishment of NICUs in developing countries with adequate equipment like portable $\mathrm{x}$-rays, echocardiography, cranial ultrasound for more detailed evaluation of this high-risk population.

\section{Conclusion:}

Preterm neonates in $\mathrm{CMH}$ Sylhet are one of the contributors of NICU admissions. Neonatal jaundice, respiratory problems and sepsis are major causes for admission with PROM as the commonest maternal risk factor. Case fatality rate was significant in neonates with RDS and sepsis and overall survival rate was $91.6 \%$. Since clinical outcome was related to gestational age, early detection of high risk factors, improving antenatal care, timely interventions and early referral of high risk pregnancies to tertiary level centers might improve the survival rate.

\section{References:}

1. United Nations Inter-agency Group for Child Mortality Estimation (UN IGME). Levels \& Trends in Child Mortality: Report 2018, Estimates developed by the United Nations Inter-agency Group for Child Mortality Estimation. United Nations Children's Fund, New York, 2018.

2. Chawanpaiboon S, Vogel JP, Moller A-B, Lumbiganon P, Petzold M, Hoganm D, et al. Global, regional, and national estimates of levels of preterm birth in 2014: a systematic review and modelling analysis. Lancet Glob Health. 2019; 7: $37-46$.

3. US Agency for International Development. Nepal: Profile of preterm and low birth weight prevention and care. USAID; 2015.

4. WHO. Born too soon. The global action report on preterm birth, WHO, Geneva. Switzerland, 2012.

5. Pennell CE, Jacobsson B, Williams SM, Buus RM, Muglia LJ, Dolan SM, et al. Genetic Epidemiologic Studies of Preterm Birth: Guidelines for Research. American Journal of Obstetrics \& Gynecology. 2007; 196: 107-18.

6. Lindström K. Long-term consequences of preterm birth:
Swedish National Cohort Studies. Inst för klinisk forskning och utbildning, Södersjukhuset/Dept of Clinical Science and Education, Södersjukhuset; 2011 May 6.

7. Baron L., Hodgaman J.E., Pavlova Z. Causes of Death in the Extremely Low Birth Weight Infant. Pediatrics. 1999; 103: 446-51.

8. WHO, UNICEF. Survive and thrive: transforming care for every small and sick newborn. Geneva: WHO; 2019: 20.

9. Abbasi KA. Neonatal Disease Profile in Larkana before and after Establishment of Neonatal Ward. Journal Pakistan Medical Association. 1995; 45: 235-6.

10. Brewster D. Neonatology in the developing world: Part 2. Tropical Doctor. 1989; 19: 147-51.

11. Blencowe H, Cousens S, Oestergaard MZ, Chou D, Moller A-B, Narwal R, et al. National, regional and worldwide estimates of preterm birth rates in the year 2010 with time trends for selected countries since 1990 for selected countries: a systematic analysis and implications. Lancet. 2012; 379: 2162-72.

12. Ochoga MO., Michael A, Abah RO., Dabit O, Ikuren I, Ebonyi A. Risk Factors and Outcome of Preterm Admissions in a Special Care Baby Unit of a Tertiary Hospital in North Central Nigeria. Open Journal of Pediatrics. 2018; 8: 11725 .

13. Wagura P, Wasunna A, Laving A, Wamalwa D, Ng'ang'a P. Prevalence and factors associated with preterm birth at Kenyatta national hospital. BMC Pregnancy and Childbirth. 2018; 18: 107.

14. Rahman A, Rahman M, Pervin J, Razzaque A, Aktar S, Ahmed JU, et al. Time trends and sociodemographic determinants of preterm births in pregnancy cohorts in Matlab, Bangladesh, 1990-2014. BMJ Global Health. 2019; 4: $1-9$.

15. Paudel L, Kalakheti B, Sharma K. Prevalence and Outcome of Preterm Neonates Admitted to Neonatal Unit of a Tertiary Care Center in Western Nepal. Journal of Lumbini Medical College. 2018; 6: 6.

16. Gupta A, Shetty D, Madhava KK. Prevalence and Consequences of Preterm Admissions at the Neonatal Intensive Care Unit of Tertiary Care Centre in South India: A Retrospective Study. International Journal of Current Advanced Research. 2017; 6: 3728-30.

17. McGil Ugwu GI. Pattern of Morbidity and Mortality in the Newborn Special Care Unit in a Tertiary Institution in the Niger Delta Region of Nigeria: A Two Year Prospective Study. Global Advanced Research Journal of Medicine and Medical Sciences. 2012; 1: 133-8.

18. Zeleke BM, Zelalem M, Mohammed N. Incidence and Correlates of Low Birth Weight at a Referral Hospital in North-West Ethiopia. The Pan African Medical Journal. 2012; 12: 4 . 
19. Kunle-Olowu OE, Peterside O, Adeyemi OO. Prevalence and Outcome of Preterm Admissions at the Neonatal Unit of a Tertiary Health Centre in Southern Nigeria. Open Journal of Pediatrics. 2014; 4: 67-75.

20. Kuppusamy N, Vidhyadevi A. Prevalence of Preterm Admissions and the Risk Factors of Preterm Labor in Rural Medical College Hospital. Int J Sci Stud. 2016; 4(9):125-8.

21. Uma S, Nisha S, Shikha S. A prospective analysis of etiology and outcome of preterm labor. Journal of Obstetrics and Gynecology of India. 2007; 57(1): 48- 52.

22. Shrestha S, Dangol SS, Shrestha M, Shrestha RP. Outcome of preterm babies and associated risk factors in a hospital. Journal of the Nepal Medical Association. 2010; 50(180): 286-90.

23. Abiodun OO, Attah RA. Risk Factors of Preterm Deliveries at Aminu Kano Teaching Hospital, Kano. Nigeria South Asian Journal of Management Sciences. 2012; 1: 3-10.

24. Onyiriuka AN. Twin Delivery: Incidence and Perinatal Outcome in a Nigerian Mission Hospital. Bangladesh Journal of Medical Science. 2011; 10: 45-51.

25. Engle WA, Kominiarek MA. Late Preterm Infants, Early Term Infants, and Timing of Elective Deliveries. Clinics in Perinatology. 2008; 35: 325-41.

26. Lee YM, Goldman JC, D'Alton ME. The Impact of Multiple Gestations on Late Preterm (Near-Term) Births. Clinics in Perinatology. 2006; 33: 777-92.
27. Charearnsutsiri R, Somlaw S. Outcomes of Very Low Birth Weight Infants at Prapokklao Hospital in the First Four years of the New Millennium. Journal of Prapokklao Hospital Clinical Medical Education Center. 2004; 21: 175-83.

28. Onyiriuka AN, Okolo AA. Neonatal Morbidity Pattern in Infants Born in Benin City to Nigerian Mothers with Hypertensive Disorders in Pregnancy. Nigerian Journal of Clinical Practice. 2007; 10: 294-9.

29. Pandey K, Bhagoliwal A, Gupta N, Geetanjaly K. Predictive value of various risk factors for preterm labour. Journal of Obstetrics and Gynecology of India. 2010; 60(2): 141-5.

30. Muglia LJ, Katz M. The enigma of spontaneous preterm birth. N Engl J Med. 2010; 362: 529-35.

31. Khan MR, Maheshwari PK, Shamim H, Ahmed S, Ali SR. Morbidity Pattern of Sick Hospitalized Preterm Infants in Karachi, Pakistan. Journal of Pakistan Medical Association. 2012; 62: 386-8.

32. Onwuanaku CA, Okolo SN, Ige KO, Okpe SE, Toma BO. The Effects of Birth Weight and Gender on Neonatal Mortality in North Central Nigeria. BMC Research Notes. 2011; 4: 562.

33. Onalo R, Olateju KE. Trend and Seasonality in Admissions and Outcome of Low Birth Weight Infants in GwagaladaAbuja, Nigeria. International Journal of Tropical Disease \& Health. 2013; 3: 190-8.

34. McGuire W, Clerihew L, Fowlie PW. Infection in the Preterm Infant. British Medical Journal. 2004; 329: 1277-80. 